


\section{La dimensión ética de Alfonso Reyes en su relación con Nieves Gonnet}

Coral Aguirre Universidad Autónoma de Nuevo León

Resumen:

Las cartas de Alfonso Reyes y Nieves Gonnet presuponen una mirada más difícil que la correspondencia erudita, intelectual, jocosa, característica del escritor regiomontano. La argentina Nieves propone el giro desde su pasión amorosa sin tapujos ni ambages. En consecuencia, lo que nos proponemos es una exploración de esa zona, como señala Lévinas, más allá de la razón, una suerte de pre-conciencia donde se yergue el afecto antes del lenguaje. La interpelación de Nieves Gonnet conmueve el universo racional de Reyes, lo enfrenta al Otro. Al hacerse responsable éticamente de tal "Heme aquí" lanzado por ella, puede llegar a los límites de sí mismo, puede dejar fluir la revelación de su humanidad, y compartirla con ella.

Palabras clave: Ética, pasión amorosa, responsabilidad, afecto, permanencia

Abstract

The content of Alfonso Reyes and Nieves Gonnet's letters presuppose are more difficult view than the scholarly, intelligent and humorous correspondence characteristic of the Monterrey writer. The Argentinian Nieves proposes a turn from her passionate openly and bluntly love. 
Following Lévinas, we propose further exploration of that area beyond reason, where a sort of pre-consciousness exists, where affection stand before language. Nieves Gonnet's demands move the rational universe of Reyes, confront him to the Other. Becoming ethically responsible by Nieve's "Here I am", the regiomontano reaches the limits of himself, allowing the revelation of his humanity to flow, sharing it with her.

Keywords: Ethics, Amorouspassion, Responsibility, Affection, Permanency.

Identidad injustificable puro signo hecho a otros, signo hecho de esta misma donación del signo; siendo el mensajero mensaje, el significado signo sin figura, sin presencia, fuera de lo adquirido, fuera de la civilización. Identidad planteada bruscamente en el imperativo del "beme aqui", como un sonido que sólo fuera audible en su propio eco lanzado al oído sin complacerse en la energía de su propia resonancia.

EMMANUEL LÉVINAS

- sta es la tercera vez que abordo la experiencia epistolar de AlCfonso Reyes. Primero fue con Jorge Luis Borges, en la segunda ocasión con Victoria Ocampo y ahora el desafío es un tanto mayor puesto que la correspondencia que tratamos aquí es inédita, singular y se encuentra sin clasificar. La misma no ha sido publicada ni numerada. Consta de 30 cartas de Alfonso Reyes y 45 de Nieves Gonnet, además de una carta de Reyes a Julio Rinaldini, marido por ese entonces de Nieves, la respuesta del mismo y una letra de Perla Gonnet, hermana de Nieves, cuya amistad con AR parece asimismo muy familiar. He tenido el privilegio de que me sea concedida para un trabajo con vistas a un libro, debido a la gentileza 
del doctor Alberto Enríquez Perea con el previo permiso de Alicia Reyes, nieta de Don Alfonso.

Como en mis dos primeros ensayos, este trabajo presupone una vez más un encuentro entre Argentina y México. Encuentro signado por cuestiones ajenas a aquellos puesto que aquí develamos vínculos más íntimos y por ende más difíciles de aprehender en su íntegra dimensión. Nieves Gonnet y Alfonso Reyes tejen entrambos en estas cartas la ética de una escritura signada por lo que va del uno al otro sin alardes, pero también sin resguardo o prejuicios. Es ese flujo que dispone de los límites el que me interesa tratar.

Así, me encuentro ante un gran desafío, porque advierto que todos los signos de la relación tú/yo se ponen en cuestión en escritos de un período tan amplio (más de treinta ańos), acentuados por la pasión amorosa que despertó en uno de los convocantes el encuentro con el otro, lo cual desnudó los opuestos entre espíritu y deseo, rubricados una y otra vez por los mensajes.

Percibo, entonces, que los postulados de Lévinas respecto de este entramado que presupone el acontecer del tú/yo, subrayando la imposibilidad de ser sin el otro, se identifican con el hallazgo de algo más que un amor o un vínculo afectivo de grandes proporciones. Pareciera que en estas cartas se yergue un afecto que fue primero que la conciencia, que el lenguaje. Afecto de estar afectado por el otro, de afectarme antes de saberme, porque el otro es sed y hambre de mí mismo y, sin embargo, tan diverso, pre-conciencia sin acuerdos de la razón, sino de la primera caricia, la de la madre, de la primera morada carne y agua, del primer rostro entrevisto. El "Heme aquí" que lanza Nieves en esta convocatoria epistolar es demasiado fuerte como para poder dejarlo pasar. Doblega la acuciosidad de Reyes en pos del decoro, y su mismo orden. Y ha de transformar lo que para él sólo es una cita más, una relación sentimental que se clausura, con la posesión, en una materia preciosa que quizás también él adivina no como puro Yo completo y 
soberano, sino por los resquicios de una pre-conciencia basada en el afecto.

Plantas descalzas, húmedas de nubes. Nieves: en quien la constancia hace veces de ternura (porque suena mucho su metal argentino) (Reyes, 1927: 37)

Como si desde el primer día supiera que esa constancia hecha ternura lo abrigará en todo tiempo hasta su muerte.

De modo que he decidido transitar por esa apelación propuesta en cada letra, que pone en cuestión lo que he tratado hasta aquí. No se trata de Victoria Ocampo haciendo mohín social, ni de la hermandad de Reyes con Borges por su pasión literaria. ${ }^{1}$ El "Heme aquî" tan poderoso de Nieves sacude la "buena costumbre" de escribir la carta en busca del receptor previsto. Nieves no prevé a Alfonso, lo interpela, quitándolo de su papel de intelectual famoso, incluso cuando lo admira y lo lisonjea.

De más está decir que vuelvo a subrayar la condición de la epístola en tanto presente equívoco ya que se dobla en dos, dos presentes para una misma letra, la del emisor y la del receptor. Hay que advertir la ficción que toda vida expuesta en palabra significa. Y considerar la carta como la medida cultural de un tiempo, un medio, una costumbre. Y agregar a ello lo que cada escriba vislumbra del otro, cómo lo quiere conmover o asombrar o bien disfrutarlo. La dimensión epistolar es esquiva y caleidoscópica: un aleph que satura el encuentro en la medida en que escrito en soledad se construye permanentemente con la voz del otro, haciendo que las palabras y las frases se dilaten en una experiencia doble, diálogo y monólogo a la par. Porque de un lado y del otro, cada epístola integra y revela la figura de quien va a leer y responder. Es un espejo

${ }^{1}$ Ver Las cartas sobre la mesa, la relación Borges/Reyes (2009) y Cartas del Sur Correspondencia de Alfonso Reyes con Victoria Ocampo (2012) de mi autoría. 
que habla tanto del que escribe como del que lee. La integridad de la carta sólo puede completarse con las dos figuras reunidas. Y, así, toda correspondencia no sólo presupone encuentro sino también ruptura: lo que no pude añadir, lo que no me dijiste a tiempo, aquello que se quebró por una interpretación sin voces que garantizaran mi afecto o desafecto. A pesar del apóstrofe, del vocativo de la escritura, y quizás precisamente a causa de ello, la expresión escrita queda inconclusa en sus bordes. Hay algo que se subraya y no se nota, algo que propone una ironía que, o bien se trastoca en sarcasmo o bien en nadería, por la ausencia de tonos, acentuaciones, suspensos o timbres conocidos por ambas partes pero trastocados a la hora de ponerlos en la página. O acaso más que la voz, sea el rostro del otro lo que falte.

Por otra parte, cuando el intercambio epistolar se da entre el hombre y la mujer que son Alfonso y Nieves, se tensan los opuestos y se revela la diferencia de los organismos. La norma cultural aparece en la letra masculina, la afectiva y, por lo tanto, desordenada, caótica por momentos, en el pulso femenino que no espera a normarse para salir tumultuoso o, en su defecto, conmovido por lo que la misma escritura confiesa u omite. Hay una vibración cuya índole proviene del cuerpo afectado, el de ella.

Tú posees naturaleza epistolar que yo perdí en la adolescencia. NO [sic] sé decirte nada que valga la pena ni equivalga a tus admirables efusiones, que tanto me interesan y me conmueven (Reyes, 31/VII/1956).

En Buenos Aires, Alfonso Reyes, primer embajador mexicano en Argentina, conoce a Nieves Gonnet. Las cartas cuya cepa nos proponemos explorar abarcan la vida de ambos hasta la muerte de Reyes. Insólita permanencia del afecto y la memoria gracias a la constancia de Nieves. Legado privilegiado para quienes las recorremos con asombro y simpatía. No obstante en este viaje inédito 
lo que aparece vívido y rotundo son los lazos que de amorosos, se transformarán poco a poco en una amistad cuya franqueza se verá estimulada por cada año de conocimiento mutuo que suma. Ahí convergen, la simpatía, la pasión amorosa, los desencuentros, el amor a las letras, la educación y cultura de cada uno, la soledad, la vejez, victorias y miserias de las que estamos hechos cada uno de nosotros. El paisaje que nos propone es suntuoso.

Como decíamos arriba, Alfonso Reyes inaugura la embajada en Argentina en 1927 y su primera etapa concluirá en abril de 1930. Durante ese tiempo no hay correspondencia con Nieves puesto que hay teléfono y ambos habitan la misma geografía. Lo recuerda Reyes en carta del 10 de noviembre de 1954:

Ya en Buenos Aires me reprendias cuando yo te decía por teléfono: "Ayer no te hablé por exceso de trabajo."

Y Nieves no es Victoria Ocampo quien sí ha de enviar numerosos mensajes al nuevo embajador para llamar su atención aunque lo vea a diario. Y además porque Tandil de por medio, una y otra vez Alfonso y Nieves hallarán un modo mucho más íntimo de encontrarse.

Sin embargo, la primera correspondencia entre ellos, la inicia Nieves antes de conocer personalmente a Reyes y data de 1926.

Diciembre de 1926-

Buenos Aires

Querido y simpático Alfonso!

He dudado un rato entre Alfonso o amigo- "Yo sé que seremos pero no soy aún"... "amigo? Alfonso?... total para Reyes es lo mismo; cuando él escribe "querido amigo" hay más inteligencia que amistady como hay tanta, también la derrochará cuando tenga la amabilidad de contestar mi carta.

${ }^{2}$ La transcripción de las cartas se ha hecho con los subrayados, los signos y los caracteres que dispusieron sus autores. 
¿Querrá Ud. Saber quién soy? Me apresuro a defenderme antes que me presenten a $U d$. Amigos comunes mexicanos; $U d$. Comprenderá muy bien por qué.

Soy una insignificante Señora (hasta me da risa cuando me digo Señora) de una pequeña casa sin ninguna pretensión pero de "mucha sinceridad" (como en el cuento gallego) adonde Ud. Frecuenta en espiritu casi tanto ya, como los pocos amigos que lo hacen hace 20 años. Con decirle que hemos sentido la muerte de Bobby y creemos que será bueno el perro de Freimann, ¿hizo plata al fin; ¿no?

Lo que no le perdonamos es que de sus asuntos amatorios, nos cuenta Ud. Muy poco y nos obliga a conjeturas poco agradables para Ud.- La Señora que a su lado se sentó en aquel banquete- "Qué malucha será"-Sus apreciaciones maliciosas de la vida de París"poco sabrá".-En fin, es mejor que sea Ud. más explícito. En cuanto a las cosas serias, el pobre Pedro se ve en figurillas para tenernos contentos. Cuando se pasa mucho tiempo sin leerse carta suya, le ponemos mala cara y creo que hasta lo hemos insultado alguna vez y el hombre desentierra papeles viejos (siempre nuevos) y nos va asi dejando contentos. Inútil decirle que nos conquistó Ud. desde las primeras lineas y demás decirle lo agradable de sus apreciaciones lo simpático de su mirada hacia el mundo, lo joven, audaz y graciosa de su frase, lo ameno de su cuento, el ambiente humano y cordial que emana de su espiritu! ¿Cómo será Ud. tratado?! Su cuerpo será mejor o peor que su espiritu, que su literatura. No quiero darle las noticias que tenemos de Ud. en cuanto a eso; al fin, noticias de mexicanos. ¿Como lo habrán hecho sufrir?! Y son simpáticos esos canallas! Amado —Caso- dejado en nuestras vidas tal perfume intenso e imperecedero que, andando por estos mundos tan mal todas esas cosas, se adora casi con fetichismo.

Escribanos; para hacerlo trate que sea lo más libremente posible (en cuanto a las noticias que de nosotros pueda tener por sus compatriotas) y si nos han olvidado como olvidan las fieras de la selva a la tribu de monitos por insignificantes; mejor.

Cuéntenos cosas del mundo que parece más civilizado que el nuestro; Ud. lo hace con tanta gracia! Es cierto que en este momento "los soldados de la guerra intelectual" están descansando demasiado? ¿Se 
siente en aquel ambiente de mayor ebullición que el nuestro que las cosas van a cambiar y para mejor? ¿El transicionismo es también alli el manjar preferido de charlas y ambiciones espirituales? Cuéntenos... sobre todo lo que Ud quiera pero por favor no me haga envidiar por más tiempo a Pedro, a Ícaza etc.

Un fuerte abrazo de

Nieves

He preferido dar a conocer la carta íntegra porque ello nos ahorra descripciones sobre la índole de Nieves. Pero, ¿quién es ella en verdad?, ¿quién es María Nieves Gonnet a quien siempre se nombra de Rinaldini? Por mi parte he decidido llamarla como la cita Alfonso Reyes a partir de cierta data. La fama de uno y la anonimia de la otra dificultan un perfil íntegro.

Los datos que nos constan son los siguientes: perteneció a una clase acomodada que se codeó con la élite de Buenos Aires. Casada con el crítico de arte Julio Rinaldini de pocos blasones pero bastante reconocimiento intelectual, es ella quien aportó el acervo de clase y la economía. Con él concibió tres hijos, una mujer y dos varones. A su vez fue hija de Luis María Gonnet Navas, diputado de la Nación, y de María Eugenia Demaría Arana, ambos enterrados en La Recoleta. Dato, este último, que proclama la herencia familiar, allí se encuentran sepultados la mayoría de las figuras más representativas del país.

El contenido de esta carta nos sugiere un conocimiento previo de Reyes y al mismo tiempo abundante de su persona.

Por ejemplo, las cartas de Reyes las leyó mi padre en casa de Nieves Gonnet de Rinaldini en grupo de amigos. En esa casa se llevaban a cabo reuniones intelectuales en las que participaron además de mi padre. Alberto Gerchunoff, Amado Alonso, Maria Rosa Oliver, Alfonso de Lafinur, Pedro Miguel Obligado y los visitantes de turno: Sanin Cano, José Moreno Villa, Federico García Lorca, Max Henríquez Ureña, entre otros (Henríquez Ureña de Hlito, 1993: 112) 
He aquí por qué Nieves lo sabe todo a propósito de Reyes aun antes de conocerlo. Desde otro sesgo, la carta revela la tradición de sus veladas los días viernes, famosas dentro de la élite intelectual de Buenos Aires al igual que las de Victoria Ocampo los domingos en San Isidro, adonde también asistía el regiomontano. Desde Miramar, en Enero de 1927, el amigo entrańable de Reyes, Pedro Henríquez Ureńa, le comenta antes que el primero llegue a Buenos Aires:

No sé lo que dirán los lectores casuales o los que van a ver cómo es Alfonso Reyes; pero entre cierta gente existe l'alphonsisme... ya ves Nieves, Perla y su grupo (Henríquez Ureńa, 1927: 406)

En cartas posteriores de Nieves, se dibuja cómo pudieron suceder tales veladas:

Qué lindo sería estar en constante tertulia los pocos que hemos quedado... habrian las dos o tres horas antes de almorzar con su clima propio y las tres o cuatro horas de la tarde para charlar hasta por los codos, evocar, recordar, llenar de ingenio lo acumulado, todo.

Estas líneas, que pertenecen al 20 de septiembre de 1959, forman parte de la anteúltima carta que enviara a México; no obstante, Reyes nos da un perfil más sugestivo:

Nieves Gonnet de Rinaldini es una de las mujeres más notables de Buenos Aires. Vive un poco aparte de la sociedad, porque tiene demasiado talento para aguantar eso, y por ciertas historias penosas que le aconsejaron cierto oportuno aislamiento hace muchos años. Tiene cenáculo literario, y Pedro Henríquez Ureña la adora a su manera. Su esposo es un hombre agradable e inteligente, muy discreto. Su casa ha sido posada familiar de todos los mexicanos ilustres (sólo de esos) que han pasado por las tierras del Plata. Alli se adora la memoria de Nervo y se recuerda con vivo afecto a Caso, a González Martínez, a 
Urbina, a Vasconcelos un poco menos porque creo que anduvo distraido por otras regiones, a Pellicer, a Montenegro. Nieves sería perfecta si fuera francesa. Ella pretende que su apellido familiar es francés, y que su padre lo era. Pero yo creo haber descubierto que es de extracción catalana. $Y$ es metálica, gritona, acerada, como buena argentina $y$ buena catalana. Pero vale mucho, y en ella la constancia sustituye del todo a la ternura (Reyes, 1928: 93).

Pero no sólo por eso hemos incluido entera su primera epístola. Hay una temperatura que propone el juego y la broma, que le quita seriedad al enunciado, que recala en sugerencias imprevistas en un afán de burlarse de la propia palabra. Nieves íntegra esto desde la primera letra. Admiradora del hombre inteligente, hace una alusión a sí misma como de poca cosa, de un ser frágil y dudoso al cual no hay que dar importancia, del mismo modo que el propio ambiente que carece de las sutilezas del Centro, es decir Europa, y acaso sobre todo Francia. Una vez más, surge una suerte de metáfora entre la índole femenina y la de América Latina, que denota la falta de autoafirmación y autoestima en la primera parte del siglo XX.

He incluido también esta carta para percibir rápido la entraña femenina hecha de restos provistos por los hombres. No es mi intención una defensa del género ajena a este ensayo. Propongo, por el contrario, advertir por medio del perfil de Nieves, la mujer hecha de sí misma y del Otro, léase, el orden instituido. Características tan fáciles de vislumbrar como la educación autodidacta, incluso en las hijas de familias ricas, la condición privada de todo su hacer, aun en las vías que le proponen su salida al mundo como la carta o la velada. Nieves abre las puertas de su casa para que se luzcan los hombres con su verba "llena de ingenio" y ella pueda recibir la educación de la que carece, aunque no sea más que de oídas. Entonces, lee lo que proclaman esos intelectuales, a Joyce o a D.H Lawrence. Hay que aclarar que refiero únicamente al marco 
de la época en que discurre la correspondencia y a las citas de la propia Nieves.

Estoy por meterle diente al Ulises de J. Joyce, me han picado a curiosidad las uiltimas criticas provocadas a raiz de la traducción. ;Qué buen literato es Pierre Louys! iQué sin desperdicio, todas las buenas publicaciones francesas del momento, me acordaba de que decias últimamente que "qué sinceros son"! (Nieves, 11/II/1930)

Sobre todo, haciendo caso a los más admirados como lo es su amigo intelectual más notable y querido, me refiero a Pedro Henríquez Ureña. Prueba de ello estos entrecruces. En mayo del mismo año éste le manifiesta a Reyes.

Estoy leyendo los Assorted articles que reunió D. H. Laurence-el de México: —antes de morir. ¡Qué maravilla! (Henríquez Ureña, 1930: 423)

En agosto, se puede sospechar que deseosa de mostrar ante el hombre que se ha vuelto su amado, su fina visión crítica, Nieves se apresura (creemos que luego de platicar con Pedro), a sugerirle la lectura como un hallazgo propio.

Agosto 7-930 Buenos Aires

Alfonso: tenía la intención y en el apuro de mi carta última se me olvidó pedirte compres "Assorted Articles de D. H.Lawrence. Primero porque yo he sido feliz, en lo más profundo de mis dominios emocionales! Leyéndolo. Luego porque dicen los intelectuales que tiene verdadero valor, y por último porque deseo mucho saber el efecto que a ti te causa ;no es efecto lo que tienen que causar las ideas (me entra un pánico de equivocarme en una de estas cosas cuando se trata de ti, aunque en el fondo no me importa un pito!) 
Y por fin el deslumbramiento de un corazón que se "prende", se enamora sin resguardo, frente al otro ser, el hombre, cuya intención fue quizás grosera, poseer el cuerpo de la hembra, hacerla suya un instante y reflejarse, verse a sí mismo, en los ojos que lo sellan, admirar-se.

Voy entrando en la sociedad porteña, que realmente es interesante y de trato excelente. No sólo me he quedado, digamos en el límite de Nieves Rinaldini, sino que estoy plenamente en Victoria Ocampo... (Estrada/Reyes, 1927: 46)

No obstante ser atrapado por la relación entrambos, se agudiza, se vuelve entrańable por oposición a la de Victoria Ocampo que siempre se mantiene. Esto vemos largamente en sus cartas, en un plano confesional aparente, con una suerte de inclinación a trastocar lo íntimo en ironía, burla o juego (Reyes, 2012). El afecto de Reyes por Nieves se hace patente en estas líneas a propósito de un personaje indeseable de su entorno:

...Soporté su amistad un tiempo por darle gusto a Nieves. ¿Cómo voy a negarle nada a Nieves, Genaro? 10 de julio de 1928. (Estrada/ Reyes, 1927: 142)

Dice Paul Ricoeur que la condición ontológica del ser humano es tal que lo hace ser más grande y más pequeño que su propio yo (Ricoeur, 1960: 26). Así, Reyes discurre entre un sentimiento de admiración y ternura imposible de medir como el que apreciamos más arriba. Por oposición, al mismo destinatario le dirá años después:

No sé si es que PHU se acobardó con las censuras que oyó en casa de Nieves, donde tiene ciertas razones de mujer que pasó de los cuarenta para quejarse de mí (Reyes, 1931: 77). 
Ahora bien, situémonos en el contexto que propone la correspondencia. Luego de la primera carta de Nieves enviada antes de conocerlo, volvemos a encontrarnos con las dos siguientes desde Necochea, ciudad al borde del mar y próxima a Tandil. Reyes se encuentra en Buenos Aires cumpliendo sus funciones de embajador. Por diversas menciones en su Diario y en el epistolario con Genaro Estrada, sabemos que Tandil, esa ciudad pequeńa y transparente en la pampa húmeda, con su sistema de cerros suaves, su rica fauna y flora que don Alfonso tanto apreciara en sus versos pampeanos, es el sitio de sus encuentros. Allí, con el pretexto de aislarse para trabajar mejor, discurrió la estación de sus amores. Desde esa región, lanza Nieves su primera nostalgia, la que se anuncia con la partida de él a su nueva embajada en Brasil. Selecciono de las dos cartas la segunda que corresponde a la despedida. El amado se está yendo, sugerido por la acuciosidad del encabezado.

\section{Buenos Aires}

5 menos $10 \mathrm{~m}$. Abril 2-9 (1930)

Alfonso: entre uno y otro sueño, envuelta en la pureza de la madrugada, quiero antes que te vayas repetirte la impresión de profundo sentimiento que has sabido dejar en mí, nadie como tú me ha dado la emoción honda de haber dado con el sentido más intimo de mi personalidad (que palabra pretenciosa)

Hubiese querido estar cerca de ti estos últimos días; aunque sé que alli vas a estar mejor que aqui nunca estuviste bien, toda partida es fea pero, egoistamente lo he evitado, mi vida está tan llena de sacrificios!

No por dejar de ser epiléptica esta separación deja de ser menos terrible, pero aunque corporalmente no nos veamos más, me siento dentro de tu orbita espiritual, en cierto modo me quedo contigo, con todo lo bueno que me has dicho, con todo lo leal y noble que has sido conmigo, con todo el perfume especial y excepcional que emana de tu espiritu. 
Mis amigas, después de haber sufrido se quedan con la estimación más exquisita de ti y cuando el secreto de la perspectiva empieza a hacerse sentir será el grande entre los grandes: Mi marido, mis hijos, mi hermana!

La vida!...es, para todos espiritu, siempre cruel y nosotros seguramente no escapamos como excepción!

¡Mi mejor, mi más grande, mi más profundo abrazo!

Tu

Nieves

Tanto por su diario con escuetas menciones al vínculo que ha de crecer con los años, como por la correspondencia a su amigo Estrada, vislumbramos apenas el extrańo modo que tuvieron estos dos de acompańarse a lo largo de su vida, por la obstinación de Nieves, es cierto, pero asimismo porque Alfonso lo propició en cada epístola que, incluso a regañadientes en algunos casos, envió a su interlocutora.

Ahora Alfonso Reyes ha partido, ya no lo obtendrá más por fuerte que sea su apóstrofe, puede entonces dar lugar a su más recóndita pasión. Puede dar nombre sin ambages a lo que la acucia, detallar por ejemplo el rostro del amado, y regocijarse en la memoria.

Buenos Aires abril 29 -930

Alfonso: ;Te quiero más que nunca y siento positivamente que el nervio... de mi médula se hace gracias a la excitación que tú le provocas! Todo lo demás de mi vida es ¿sueño? ¿suerte? y lo hago a ojos cerrados se abren sólo para mirarte y complacerse en la preciosa hechura de tu nariz, en esos misteriosos puntos luminosos que tienes en los rinconcitos de los ojos joh! Yo sé cómo viajar "de luxe" (como dice Maria Cecilia) Y la inteligencia? Esa si que está ocupada! Lo complejo, lo intenso, lo casual, lo integro, lo claro, jcuántas cosas! ¿Y el de la batuta? Dolor, dolor siempre dolor y más dolor y allá, en el fondo, el sostén unico la esperanza de encontrarse alguna vez aqui abajo o la 
cita para mundos mejores con todo lo magnifico de lo desconocido, con todos los fuegos de artificios de la fe.(Fragmento)

La respuesta de Reyes brilla por la forma en que soslaya la entrega de Nieves:

Río de Janeiro, 23 de julio de 1930

Nieves, querida mía:

La presencia de Pedro Miguel obligado en Buenos Aires, que él explicaba como el resultado de una súbita decisión, de un arrebato; que otros creian explicarse por la llegada de Rosalina Coelho Lisboa, $y$ los más picaros, como un afán de competir con Arturo Capdevila, hubiera sido todavia más agradable si tú o Perla se hubieran decidido a acompañarlo. - Todavia mi casa no merece amigos, pero muy pronto estará en estado de merecerlos, y entonces...

Su carta sigue en el mismo tono por dos cuartillas hasta el final:

Bésate a ti misma por mi cuenta, Te quiero tanto. Alfonso

Este fragmento es sólo la muestra de su reticencia, porque no sabe o no puede entregarse a sus efusiones, como llama Reyes a las cartas de ella.

La otra respuesta es quizás la de su literatura. El 3 de julio de 1930 escribe Calidad Metálica, imposible dejarlo de relacionar con Nieves puesto que desde el primer momento en que la conoce él la define así, como calidad metálica.

Ninguna mujer me ha querido con tanta precisión como tú. Es una precisión tan grande que casi es dureza. Es una dureza tal que ya es solidez. Es una solidez toda sustantiva. Cuando quiero escribirte sobre nuestro amor, me sobran todas las palabras, se me vuelven de agua y me parece que quiero envolver y encerrar en agua una cosa sólida y dura (Reyes, 1930: 43). 
Nieves se retoba, iracunda, lo azuza. De la carta del 4 de agosto de 1930 extraigo los tres fragmentos siguientes:

Ni me retas, ni me apruebas, ni me desapruebas, dejas pasar el tiempo y salvas el silencio caballerescamente [sic], al primer pretexto.

Luego sugiere la separación con Rinaldini que efectivamente ha de suceder una década después:

Yo sé que debo hacer como que Rinaldini no existiera serenamente y ahi tienes que a veces de nada vale el haberlo comprendido, sufro y me enloquezco.

Y concluye más retadora que nunca con la ironía propia de su raza, ahora sí semejante a Victoria Ocampo a quien no obstante no ha de nombrar una sola vez en su voluminosa correspondencia:

Y ahora padre, me acuso de todas las lindas frases de mi vida pasada, prometo aumentarlas con las dos o tres últimas palabras igualmente lindas y un gran abrazo como acto de contrición.

Todavía, para completar la carta cuyos fragmentos hemos transcripto, con un pedido que se le había olvidado, agrega el 7 de agosto.

Bueno pues, cualquier cosa que sea lo que te provoque su lectura y si es que nada te provoca también, pero sé bueno y sencillo, no me salgas con una de esas fanfarronadas (cierra la boca...

Y sucede el silencio casi un año entero, hasta el 5 de mayo de 1931. Después, cuando le envía una carta muy corta, para sus acostumbradas ocho a diez cuartillas, muy terrenal, con datos sobre la rea- 
lidad, el entorno político, la familia y sólo un párrafo que se parece a Nieves:

Conciencia del valor de los hechos como fin y medicina y ausencia de hechos, hechos hacia afuera, hacia adentro me estoy desfondando a fuerza de profundidad y mareando porque todavía no he llegado a mi suela de novia. Todo esto quiérele decir que mi vida gira sobre la misma falla de eje. El eje existe pero guardado para una oportunidad que no llega. Bonita vida ¿verdad?

Luego se despide casi con mesura: "muchos afectos". Y ya no hay más "efusiones” de la paciente y metálica argentina. Entonces Reyes envía un mensaje largo, cálido, que concluye curiosamente con una pregunta que él se sabe de memoria:

Nieves — di la verdad, al cabo no pasa nada-_ime quieres? Tú has visto bien: yo te quiero.

Sin embargo, no hay respuesta. Reyes ha sido vulnerado en su ser, aquel conformado éticamente por la presencia del Otro, por la inclusión del Otro en sí mismo: porque su Yo vinculado al Tú de Nieves se convierte en algo que va más allá de lo que preveía para él. Y ello presupone la responsabilidad ética por encima de los límites que él mismo entiende como suyos. Hay una inter-ferencia de inferre, in: 'penetrar', ferre: 'dentro de sí. Nieves es radicalmente diferente a él. Esa entrada del Tú, del "Heme aquí" lanzado por ella, donde él se reconoce en la imputación, le permite vincularse mejor consigo mismo. Como un retorno a sí, a través del Otro. Y todo ello va mucho más allá de su conciencia. Es por eso que me pareció oportuno tratar la correspondencia desde la ética de Lévinas. Porque lo que yo percibo entre Nieves y Alfonso es una aventura particular que nada tiene que ver con el intercambio de cartas por razones afectivas, culturales, sociales o políticas. No hay 
intento de predominio ni de ostentación, tampoco de comunicar en primer lugar eventos de la propia vida. Este es un ejercicio cuyo carácter relevante es el de "dejar ser al otro" lo cual robustece el vínculo, lo alarga sin anular la relación ya que el tú/yo implica un "entre dos", ni fusión ni anulación de uno por el otro. Más adelante, las cartas que discurren hasta 1959 ofrecen larga prueba de generosidad y reconocimiento a ese Otro donde también estoy Yo.

-Un dia, estaba yo insolado en Tandil. Tú me obligaste a guardar cama, en tu alcoba, lo volviste todo fresco y blanco. ;Qué reposo, qué suavidad! ¿Te acuerdas? Nosotros estamos ahora tan solos en esta casa inmensa... ¿Qué será aquello, Nieves, aquello que andábamos buscando o que veníamos a buscar a la tierra y que se nos olvidó al nacer? Menos mal que tú todavía tienes para consolarte tu creencia en un Dios antropomórfico, un Dios que concede audiencia en sus oficinas; de tal hora a tal hora, mientras se canta misa; que toma nota de lo que nos pasa a los hombres, $y$ da órdenes a sus arcángeles, dominaciones y potestades. Dichosa tú después de todo. No sabes lo que tienes. (Si lo sabes, vaya si no, naturalmente que sí ¡Tú, lo que no sabes, es porque lo adivinas).-

R 3 nov. 1931

Tampoco hay respuesta. Entonces Alfonso Reyes lanza su "do de pecho". Entiende, acaso sin proponérselo, que el amor de Nieves por él necesita de toda la verdad, la verdad ética del ser humano allí presente, al borde de sus líneas, en los arabescos de la palabra, como rasgos del rostro que no está presente.

Veamos ahora cómo sucede esto flagrantemente, en una carta posterior al poderoso "Heme aquî" cuya omisión a la invitación del Tú, nos había sorprendido. Reyes se expresa así:

Río 5 de enero de 1932

Nieves: Yo he estado conteniéndome, he estado jugando a la frialdad lo más que he podido. Pero ¿qué objeto tiene hacer esto? Tus pape- 
litos cada vez me conmueven más, porque cada vez me estás diciendo las cosas de un modo más directo y preciso. Los últimos se me entraron como cuchilladas.

Ahora comprendo los fracasos del teléfono. Será cuando Dios quiera. Sin necesidad de que "me veas la expresión y el gesto", te aconsejo en serio, y con conocimiento de causa, que cuides esos ojos. Mira que se trata de "esos ojos".- Y cuando lo acabes, mándame, sí, el libro de Chestof.

¿De modo que tú crees sinceramente que mi dolor va a importarle a nadie? No hables de dejarme ir por escritor, de echar el alma en letras. - La vocación de las letras ha sido una de las razones que me detuvo la mano cuando pensé seriamente en suicidarme.- Cuando yo tenía la edad de mi hijo, yo era un líder de estudiantes; tenía éxitos oratorios todos los dias; una estupenda cabellera rubia; era campeón de esgrima francesa en la Escuela Preparatoria, y de esgrima italiana en el salón de Timperi; era futuro príncipe heredero (mi Padre iba a ser Presidente cuando le diera la gana, y era ya uno de los prestigios más poderosos, era un objeto de adoración mística). Yo, que me daba cuenta de lo que son las vanidades politicas y veía los resultados ya en la casa de mi hermano (que era el primer bufete de abogado de la República) no me dejaba marear con los éxitos. Además, me defendian dos cosas: mi melancolía enfermiza, natural, que de tiempo en tiempo subia a flote y me borraba todos los halagos de la vida,- yo entonces lloraba mucho a solas; $y$, por otra parte, mis amigos. Mis amigos se llamaban Pedro, Caso, Vasconcelos: me decían la verdad, no me dejaban envanecerme.- Me enamoré de un modo único, espantoso, asolador, indescriptible; pasé por todo, lo afronté todo. En mi casa habia el respeto pánico a la autoridad de mi padre, y la reacción sagrada de la intangible voluntad de mi hermano mayor, en cuya casa yo vivía entonces. Nada me acobardó: me hice mi nido de amor aparte. Me encerré allá con la mujer y los libros. Me impuse a todo y a todos de tal manera, que nadie se dio cuenta, Fue como el aire: nadie lo siente, nadie lo ve, y nos rodea. No tuve que luchar: fui naturalmente libre. Eso me salvó. De otro modo, yo me habría matado: Pero como el amor trae consigo sus propios sufrimientos, yo quería morir- 
me todos los días a causa del mismo amor. ¡A qué frágiles pretextos que agarraba mi vida, mi instinto de salvación! Mira: después de un dia de estragos sensuales, de horribles tragedias de inconformidad, de lágrimas y violencias, cuando yo habia pedido cien veces la muerte, me quedaba completamente exhausto. Eran las ocho de la noche. A esa hora yo tomaba el tranvía para volver, desde el lejano barrio, a la casa familiar de mi hermano. Era tal mi fatiga, que a veces me dormía en el tranvía, pobre criatura rubia de menos de veinte años! No tengo piedad cuando me acuerdo! Entonces sentía yo que mi vida se refugiaba en su minima expresión, se aferraba a su egoísmo minimo para no acabarse. Me daba yo cuenta de que, en ese instante, Ella no me importaba, de que ya sólo me interesaba sentir la sorda continuidad de mi respiración y mi sangre, el bienestar de mi máquina biológica que seguía funcionando. $Y$ me decía yo a mi mismo, —sin duda porque me lo dictaba al oido mi ángel guardián-: "Puesto que hay horas del dia en que ESO nada te importa, debes seguir viviendo: concibes la posibilidad de una vida sin ESO. Además jacuérdate qué feliz eres cuando haces versos!" $Y$ de esto se prendía mi vida, Nieves, te lo juro. - No se lo he contado nunca a nadie. No sé cómo te lo estoy contando a ti Perdóname que lo haya hecho. Quiéreme: Haces bien, porque me hace falta, me hace bien, Calla: no digas nada. Mi mano en tu boca.

A.

\section{Y un mes después, ante el silencio de Nieves, prosigue en buscarse ante ella en completo despojamiento.}

\section{9 de febrero de 1932}

Nieves, Nieves: El día que yo envie una carta atreviéndome a no ponerle fecha, ese dia me habré encontrado a mi mismo. Todavia, no puedo. Todavia soy una pobre cosa que alza hacia arriba unos vagos tentáculos en forma de brazos de imploración.

¡Cuánta estupidez y cuánta pedantería te he escrito! ¿Quieres el secreto? Mi timidez: me asusto tanto de ser tomado en serio, que quiero justificarlo ante mi mismo y acudo a los recios recursos, a mi cultura, 
a mi literatura, a mi arte de zurcir palabras y cosas así. ;Qué tendrá que ver todo esto con los golpes de corazón, con los latidos de mar y sol que tú me envias! Espiritu incansable, naturaleza insaciable ;Cómo no se habian de cerrar sobre ti los dos horizontes! ¡Ah, qué anhelo de apretarte de veras, con brazos de espacio, de consumirte con fuego de astros, de absorberte de veras en ese ser tuyo que está más allá del muro de las palabras! ¿Y qué hace ese espejo de tu armario que no se sale hacia tu desnudez, como inundación, todas las mañanas?

Y concluye:

¿Qué descanso pensar que puedo hasta decirte esas tonterías que tú me señalas, y que nada puede hacerte variar! De modo que existe lo absoluto, hasta en esta cosa de ceniza que somos. - Beso tus cenizas, cada vez con más emoción, Nieves.

El vínculo, en ausencia, se amplifica, Reyes se permite "efusiones" a la manera de Nieves. Ella lo ha "contagiado", lo ha desbordado, se ha alargado en él. Si Reyes abunda en un espacio propio, si es visto con admiración y respeto, si incluso sus pequeńos escándalos sentimentales son recibidos con una sonrisa benévola, si se planta en el mundo con inteligencia, sensibilidad y saber, Nieves es vulnerable y carga con la mirada crítica a causa de ciertos excesos de su pasado, es frágil porque no se asienta en lo que realiza en su propia vida sino en el reflejo que obtiene de las otras, es la menor de edad, es mujer. Sobre todo lo ama, su pasión amorosa es su mayor labilidad porque él la ha tomado y la quiere pero no la elige ni la ama tal como ella lo exige. Su vulnerabilidad provoca la responsabilidad del Otro, de él. Él debe hacerse responsable de tamaña desigualdad. Para ello, necesita reconocerse, asegurar la labilidad de ella con la suya propia.

Desde el momento en que el otro me mira, yo soy responsable de él sin ni siquiera tener que tomar responsabilidades en relación 
con él; su responsabilidad me incumbe. Es una responsabilidad que va más allá de lo que yo hago (Lévinas, 1977: 207).

Sin embargo, Nieves tampoco ha de acudir. ¿Lo ha abandonado finalmente?, ¿el despertar de él, al "Heme aquî" de ella, ha llegado tarde? O, tal vez, no contamos con sus respuestas, pues se han comunicado de otra manera, quién sabe. Este período, no obstante, concluye con una nueva carta de Reyes, manuscrita, fechada el 18 de abril de 1932.

Si de algo te sirve o algo te importa, ten la seguridad de que, al revés del sueño que tuviste, ni una tilde de tus papelitos se pierde cuando llega a mi; todo lo entiendo, lo siento y hasta lo vivo, de cierta manera sonambúlica que yo tengo para apropiarme las cosas. Créelo, y que el hábito de hablar conceptualmente —que es mi pecado- no te estorbe para creerlo. Borra mis palabras. Creo que mis gestos te sirven más. Soy esotérico: me escondo detrás de las palabras, por miedo de que mi doctrina, claramente expuesta, haga daño a los otros. Asi, yo no respondo: asi, que me siga el que quiera, y venga conmigo.

Según lo que se sospecha, comienza ahora el calvario de la pasión alfonsina en Río de Janeiro, algunos dicen que por la poeta Cecilia Meireles, otros por una mujer de la alta sociedad y el resto por una muchacha de pueblo. También se dice que llega de regreso a la embajada en Buenos Aires en 1936 sumamente entristecido, como lo prueba su Diario, que nunca fue revelación de nada íntimo sino de citas, encuentros, presentaciones, etc.

Aunque ha habido un quiebre, la mención de tal regreso en su Diario sin embargo, se inicia con el nombre de Nieves:

Buenos Aires, (miércoles) $1^{\circ}$ de julio 1936

Entramos a las 11 a.m. en el puerto: Nieves Gonnet, Julio Rinaldini, el Bebe [hijo de ambos]... (Reyes, 1936: 3) 
Aunque en su Diario hay anotaciones de encuentros para comer con Nieves, en la casa de los Rinaldini, o bien con Rinaldini a solas, ahora Reyes se encuentra enredado en una de sus últimas aventuras pasionales, esta vez con la actriz argentina Iris Marga, notable por su glamour y su belleza de rubia despampanante.

De todos modos ha terminado la primera etapa de la Correspondencia Alfonso /Nieves, que será retomada hasta la década de los cuarenta por una reacción de Nieves ante la carta que Reyes envió a Rinaldini y que éste le muestra:

Febrero 25-40

El imbécil de Rinaldini me dio a leer su carta con las dos idiotas palabras del final.

Estos dos fuertes adjetivos me descargan la presión, que como animal, me provoca, la idea de que, si Vdes. no han tenido la suerte de ...Marzo y ya vés: ini rastros de "acomodo" con la vida.

Nieves

Voy corriendo a echar ésta carta para que el tiempo no me arrepienta ; Ya estoy bastante intoxicada por contenimiento!

El final de la carta de Reyes a Rinaldini del 23 de enero de 1940 la transcribo para el propio juicio del lector:

Saludos muy cariñosos a todos, en su casa y fuera de su casa. Ojalá se realice ese plan de que usted me habla al oído. No deje de informarme de lo que haya.

El afecto de los mios y un abrazo de

AR

Alfonso Reyes

Sin embargo, durante la década de los cuarenta, las cartas que se cruzan o, al menos las que constan en mis manos, son sólo otras tres, de las cuales, la primera, expresa los sentimientos de cuidado y afecto que pone Reyes en la relación con Nieves: 
México, D.F. a 29 de marzo de 1940

Sra. Doña Nieves G. de Rinaldini

Junin 1160

Buenos Aires, Argentina.

Querida Nieves:-

Tu carta del 25 de febrero me llena de sorpresa. Por una verdadera casualidad, dicté en mi oficina mi anterior a Rinaldini y conservo copia de ella. He buscado en vanos las "dos palabras idiotas del final" a que tú te refieres y que han provocado tu explosión, si lo que te ha molestado es la alusión al "secreto de que usted habla al oido", puedes preguntarle a él mismo lo que me dijo y comprenderás que en modo alguno se trata de confidencias sobre su vida privada que nunca me he metido a averiguar. Si, por alguna circunstancia de que contigo no debo hacerme desentendido por la lealtad que te debo, lo que te ha molestado es lo de "saludos a los de adentro y a los de fuera" te declaro rotundamente que nunca se me ocurriría que los de fuera fueran otros que los mismos amigos de tu casa y que tú hiciste amigos mios. No me molesta tu exabrupto: más bien encuentro en él tu anhelo de saber que yo no puedo nunca ser ingrato y grosero con tu recuerdo. Esto es lo único que me importa recordar de tus palabras. Si a distancia las expresiones mias han cobrado sin saberlo yo, alguna intención que pueda lastimarte, atribúyelo a la distancia misma, pero nunca a un propósito avieso de mi parte.

Ten la certeza de que ninguno de tus actos para conmigo pueden perder su verdadero y alto valor en mi corazón. Con todos mis defectos que ya conoces, soy siempre tu devoto amigo

Alfonso Reyes

La segunda, en cambio, muestra la imposibilidad del sueño que no se ha concretado y cuya memoria ella no puede evitar. La solidez del amor de la metálica Nieves:

\section{Domingo 13 de octubre (slaño) Bs As}

10 de la mañana, mañana de sol fresca, luz de espejo sobre el río que inunda mi ventana. - Leo tu artículo "Parrasio o de la pintura 
moral-Si esta "forma" del artículo dice con "los efectos de tu ánimo" qué contenta estoy y que milagro en estos días endemoniados de confusión y de hemorragias colectivas!

Siempre he pensado que tú en lo de la belleza te sostienes y haces bien porque asi y todo, ya ves...pero eso no quita que yo no me contenga y te lo siga pidiendo

Nieves

Y, la tercera, que data del 23 de diciembre de 1941; es apenas un recado por parte de Nieves para corroborar el recibido de un "papelito" por intermedio de Arciniega desde Washington.

Es la década en que Nieves se divorcia de Rinaldini convirtiéndose en Nieves Gonnet. La época en que los hijos se hacen grandes, realizan sus estudios superiores (en algunos casos se van al extranjero para realizarlos) se casan o casados ya, organizan sus hogares. Don Alfonso ha sufrido por los avatares del casamiento de Alfonsito sucedido en 1936 y en una larga carta de la década siguiente se lo cuenta a Nieves con detalles. Cada vida se ha completado, se ha sellado de alguna manera. Nieves ha emprendido negocios propios para autoabastecerse aunque ya lo venía haciendo en tiempos de Rinaldini.

Y lo que no es menor como diría Borges, "el animal se ha muerto o casi muerto" aparentemente... En el caso de Nieves da lugar a un excesiva reiteración de lo espiritual. El anhelo, como ella lo llama, el deseo de ser amada y alcanzada en plenitud por el otro, se aminora y el espíritu, que nombra una y otra vez, da lugar a una suerte de recompensa. El estatuto del espíritu es sin duda un paradigma gramatical cuyo perfil anuncia un nuevo modo de vivir la vida, el de la melancolía. El objeto deseado se ha perdido y queda en su lugar la ausencia como desgarramiento de una parte del ser, imposible ya de curar.

De esta manera llegamos a la última década, los cincuenta, en donde las cartas se multiplican, 54 en total, 32 de Nieves y 22 
de Reyes. Son cartas de una calidad extraordinaria. Plenas de reflexiones sobre el pasado, el duro presente, las enfermedades que alcanzan los años viejos, la soledad a la que todo ser humano, pasados los sesenta, se ve enfrentado por el abandono de los amigos, a causa de la muerte de los mismos o la reclusión de cada uno de los sobrevivientes; por fin la soledad final, esa que presupone la muerte. Sin embargo, pervive un afecto por parte de Nieves que por llano y fuerte, gestado a lo largo de casi treinta ańos, conserva una pátina de amor imposible, de amor ideal, sońado, perfecto, y si acaso, la nostalgia de aquel Alfonso que fue el amado irreemplazable del lado de Reyes, como una impronta que no se está dispuesto a perder.

Abril 7- 1952 Bs. As.

¿Qué te escriba? Ahora verás las pavadas que dicen las cartas de una vieja vencida.

Y continúa añorando plena de melancolía.

Isabel mostró más fotografías viejas de su familia, en una estaba Pedro, en cuanto lo descubrieron mis ojos largué a llorar como los chicos, con ruido fuerte, abundante agua, moqueo y todo, tuve que levantarme y esconderme para no dar tanto escándalo. Ahora mismo me sorprendo al no entender el proceso. Claro que extraño a Pedro todos los días de mi vida, y cuento como se ha dicho "Esto pasó antes de conocer a Pedro y esto después".

También reflexiona con el compañero que, como ella, ha envejecido.

Ya no me miran por la calle, lo extraño, siempre me miraron; algún viejo o cuando salgo muy arreglada, uno muy joven me hace bajar los ojos, tan distinto antes, les sonreía, o con gran asombro de ellos me 
portaba como hombre y les decía "gracias". Mi físico, como el alma, vencidos...

Y, sin embargo, la misma exigencia de siempre: no hay lugar para el olvido con Nieves:

Junio 15 - 1952-Bs.As

Querido Alfonso. Por causas sociales reanudamos nuestras comunicaciones, luego tú me inventaste que si yo te escribiese tú me contestarias, estoy cansada de preguntar si hay carta de México, arde del mundo porque desde que me comunico de nuevo contigo, no dejo de hacerlo constantemente "in mente", como si fueses el unico ser viviente en este mundo. Pero no es raro. Dos asuntos agudos, profundos, graves ha tenido mi vida: mi casamiento, con todo mi ser, repleta de ilusión y fuerza; muy pronto se me derrumbó todo. Y el gran amor que sentí por vos. "El amor el amor" que me dijiste, yo no le sigo llamando "El amor a Alfonso". También eso terminó y desgraciadamente cuando a mi se me termina algo es como si se hubiese muerto en todas formas. Fijate que hace unos meses, encontré a Rinaldini en la calle, pasé a su lado, lo miré, todavía me di vuelta y era como si hubiese pasado junto a un poste que nunca, ni nada hubiese tenido que ver conmigo, y he vivido 30 años con él bajo el mismo techo, es el padre de mis 3 hijos, y fue con quien me casé tan integramente, pero el que no existe más es un Alfonso, ha quedado "vivito y coleando" Alfonso Reyes, mi amigo, el que prestó al otro, al que le debo, los momentos más álgidos de un alma jlas más puras, grandes y profundas emociones!

Por su parte, Reyes ahonda en su primer contacto con la muerte en sucesivas ocasiones. El 23 de junio de 1952 subraya:

Dije antes: "Desde que me mori en agosto de 1951". Tal es, en efecto, mi impresión: aquel ataque de infarto en la coronaria fue espantoso, me llevaron al Instituto de Cardiologia (por suerte una gran institución, y por suerte con nuestro eminente Ignacio Chávez a la cabecera 
de la cama) asfixiado, las uñas, los labios morados, y con los pulmones edematizados...

Nieves, a su manera, todavía se revuelve, la muerte en todo caso para ella es que Reyes no haya respondido a su llamado: ¡Todavía! El 15 de diciembre de 1953 lo reta:

Te creia muy bien porque me habian dicho que habian salido fuera con Orfila y al no recibir contestación a mi última carta me encogí, pensando en que cualquier distracción te alejaba del deber de nuestra amistad, porque este deber, el de la amistad verdadera y honda, herencia de un amor fracasado, no entra en las dos clasificaciones que Shaw hace del deber en las cartas a Mrs. Patrick Campbell...

Así la literatura, las obras de Reyes, su publicación en el FCE, sus artículos, siempre presentes, se articulan con los achaques de cada día y, no obstante, lo que prevalece es el afecto de ese Tú /Yo más allá de toda razón, tomándolo entre sus manos, como si se tratara de una frágil criatura a la que siempre hay que atender. Reyes cuida cada día su responsabilidad afectiva.

Pero tu recuerdo no desaparece, Nieves; y aunque tú creas que los volcanes que se ven desde el Valle de México son monstruosos, son de lo más hermoso que existe; con decirte que uno de ellos me recuerda a mi Nieves perpetua, $(6 / \mathrm{IV} / 53)$

Discurrirán las cartas, pasará la vida, lo que queda es la tozudez del Heme aqui de Nieves, su furibundo ser que clama y reclama el amor de Alfonso. Y, en ese ser tan distinto a él, Reyes encontrará la amorosa responsabilidad de responder al llamado desde el más profundo afecto. Sin pensarlo, sin racionales argumentaciones, sin logos de por medio, sólo la espirituosa sensación de ser amado más allá de cualquier pulsión reflexiva y de poder devolver la pasión con la ternura que lo conectará más hondo consigo mismo. 
10 de noviembre de 1954 Reyes

[...] gracias por tus páginas intimas. De tus reparos que hago mucho caso, pues si las tomaras tu misma en serio nunca me enviarias páginas como ésas, tan de dentro de tu corazón y llenas de un dolor comunicativo que me ha hecho estremecerme. Las naturalezas fundadas en lo absoluto, como la tuya, tienen que pagar este alto precio. Yo, pobre de mí, con ser tan terreno, me he visto en el caso de decir:

¿Qué tienes alma, que gritas

A tu manera y sin voz?

Los caminos de la tierra

No llevan a donde voy.

[...] Sería el más necio de los hombres si negara lo que te debe la firmeza de nuestra amistad. Esto no puede decirsele casi nunca a una mujer, Nieves. Que esta declaración te compense de mis involuntarias impertinencias. Bueno es que entiendas lo que te quiero y lo que te aprecio: son dos categorias distintas, de mayor a menos.

\section{Y el 31 de agosto 1955:}

Nieves muy querida y recordada:

Ni un solo dia he dejado de pensar en ti. Bien sabes que mi sensibilidad no me lo permitiría, y menos en estos momentos que estáis pasando, y menos tratándose de ti, que ocupas un lugar predilecto en mi corazón. Y no te lo digo para satisfacer tus tiernas reclamaciones. Hay cosas que no necesitan explicarse. Eres tan mía como soy tuyo y la vida nos ha juntado para siempre. [...] Sé siempre tú, sé siempre la Nieves de diamante. Te abraza cariñosamente

Para intuir que su responsabilidad es mayor porque no la ha amado tal cual ella lo merecía:

Hago mias tus palabras: "Por lo único que vale la pena de vivir en este valle de lágrimas es por el hondo sentir de dos corazones amigos, 
cuanto más sería enamorados". Pero, Nieves... No olvides que te quiere mucho-21 de enero de 1956

Finalmente la última carta, el 23 de noviembre de 1959:

Contesto, Nieves querida, tu muy expresiva carta del 15, y empiezo por asegurarte que aqui está siempre tu recuerdo, asi como el de Perla, a quien deseo la más cabal recuperación.

No hables ya de los pasados "desencuentros". Concéntrate en las emociones de nuestra amistad, nuestra armonía y nuestra comprensión.

Un elogio tuyo es siempre de oro, pues eres insobornable. Curioso: de los 40 y tantos articulos que hasta hoy me han distribuido por nuestros periódicos latinoamericanos una agencia de Nueva York, el art. Sobre los sofismas, que tanto parece haberte estimulado, es el único que se prestó a objeciones: temían que no interesara fuera de México.

¡Ya ves el crédito que merecen los intermediarios! Por lo demás, nos hacen falta, pues hasta hoy nunca he logrado que el carnicero de la esquina me dé un solomillo a cambio de un soneto.

Pronto te envio libros: que te sean gratos. Entretanto, con los saludos de casa, mi corazón.

$A R$

¿Tu situación económica? Me atrevo a preguntarte.-

Muy enfermo: ya no hay médicos, sólo laboratoristas.

Nieves representa "la presencia de un ser que no entra en la esfera del Mismo, presencia que lo desborda, fija su 'jerarquía’ de infinito" (Lévinas, 1977: 207).

Nieves ha exigido siempre que la vea, que la procure. Alfonso no ha podido escaparse, está impelido a responder a ella hasta el último día, es su responsabilidad. Así Alfonso Reyes ha hallado el límite de su propia libertad. Se ha reconocido. 
De este modo veo en la correspondencia de Alfonso y Nieves una dimensión tan extraordinaria como para observarla paradigmáticamente como el acto de vincularse a través de la responsabilidad ética basada en el afecto, por parte de Alfonso Reyes.

\section{Bibliografía}

Aguirre, Coral, 2009, Las cartas sobre la mesa (La relación BorgesReyes), Monterrey, N.L., México, Conaculta / UANL.

, 2012, Cartas del Sur (La correspondencia Victoria OcampoAlfonso Reyes y sus implicaciones en el perfil cultural de América Latina), San Nicolás de los Garza, N.L., México, UANL-Facultad de Filosofía y Letras.

Henríquez Ureña, Pedro, 1979, Obras Completas, t. VI, 19261934, Juan Jacobo de Lara (recop. y pról.), Santo Domingo, Publicaciones de la Universidad Nacional Pedro Henríquez Ureña.

Henríquez Ureña de Hlito, Sonia, 1993, Pedro Henríquez Ureña: apuntes para una biografía, México, Siglo XXI editores.

Lévinas, Emmanuel, 2002, Totalidad e infinito: Ensayo sobre la exterioridad, 6 ${ }^{\mathrm{a}}$ ed., Daniel E. Guillot (trad.), Salamanca, Sígueme (Hermeneia 8).

, enero de 2006, Ética como filosofía primera, Oscar Lorca Gómez (trad.), A Parte Rei Revista de filosofía, núm. 43, pp. 14-18.

, 2006, Humanismo del otro hombre, 6a ed., Ricardo Erhenberg (ed.), Daniel E. Guillot (trad.), México, Siglo XXI editores.

Reyes Alfonso, 2010, Diario 1927-1930, t. II, Adolfo Castañón (ed. crítica, intro., notas, fichas bibliográficas e índice), México, FCE. 
, 2012, Diario 1936-1939, t. IV, Alberto Enríquez Perea (ed. crítica, notas, cron., apéndices y fichas bibliográficas), México, FCE.

, 1994, Obras Completas, Ficciones, t. XXIII, José Luis Martínez (intro.), México, FCE.

Ricoeur, Paul, 1991, Finitud y culpabilidad, Alfonso García Suárez y Luis M. Valdés Villanueva (trads.), José Luis Aranguren (pról.), Buenos Aires, Taurus Humanidades. , 2008, Si mismo como Otro, Agustín Neira Calvo (trad.), México, Siglo XXI editores.

Zaïtzeff, Serge I., 1993, Con leal franqueza Correspondencia entre Alfonso Reyes y Genaro Estrada 1927-1930, Serge I. Zaïtzeff (comp. y notas), México, El Colegio de México.

(Recibido: 14 de enero de 2015, aceptado: 23 de marzo de 2015) 